\title{
RESTRIÇÃO DE TRATAMENTO POR PLANOS DE SAÚDE E O PAPEL DA AGÊNCIA NACIONAL DE SAÚDE SUPLEMENTAR: UMA ANÁLISE HERMENÊUTICA DAS DECISÕES DO SUPERIOR TRIBUNAL DE JUSTIÇA ${ }^{1}$
}

RESTRICTION OF TREATMENT BY HEALTH PLANS AND THE ROLE OF THE NATIONAL SUPPLEMENTARY HEALTH AGENCY: AN HERMENEUTICAL ANALYSIS OF THE DECISIONS OF THE SUPERIOR COURT OF JUSTICE

\author{
Eduardo Rocha Dias \\ Mariane Paiva Norões
}

\section{RESUMO}

Este artigo objetiva analisar as decisões do Superior Tribunal Justiça (STJ) envolvendo restrição de tratamento por planos de saúde, a partir da teoria dos direitos fundamentais e da nova hermenêutica constitucional. A controvérsia está na interpretação-aplicação da regra que autoriza às operadoras de saúde a exclusão de determinados procedimentos e produtos da cobertura dos planos de saúde, frente à efetivação do direito fundamental à saúde dos consumidores. Verificou-se, pela amostragem realizada, que o STJ afastou a norma preexistente, sem, contudo declarar a sua inconstitucionalidade, interferindo, assim, na função primária do Poder Legislativo e na interpretação da norma pela agência reguladora.

Palavras-chave: Direito à saúde. Plano de saúde. Nova hermenêutica constitucional.

\section{ABSTRACT}

This article aims to analyze the decisions of the Superior Court of Justice (SCJ) involving restriction of treatment by health plans, based on the theory of fundamental rights and new constitutional hermeneutics. The controversy is in 
the interpretation-application of the rule that authorizes health care providers to exclude certain procedures and products from the coverage of health insurance plans, in face of the realization of the fundamental right to health of consumers. It was verified by the sampling carried out that the SCJ removed the pre-existing norm, without, however, declaring its unconstitutionality, thus interfering in the primary function of the Legislative Branch and in the interpretation of the norm by the regulatory agency.

Keywords: Right to healthcare. Health insurance. New constitutional hermeneutics.

\section{INTRODUÇÃO}

A sociedade ocidental, no século XIX e parte do século XX, viveu sob a égide do Estado Liberal. Neste momento, emerge o positivismo jurídico, o qual construiu a ideia de que o ordenamento jurídico - composto exclusivamente por regras - oferece apenas uma resposta para cada caso concreto. Assim, caberia ao intérprete tão somente o trabalho intelectual de encontrar essa solução, fazendo uso do tradicional método da interpretação literal, que levaria a revelar a vontade do legislador (mens legis). Não existia controle da lei pelo Poder Judiciário. Ao contrário, a decisão judicial era mais uma resposta obediente ao ordenamento jurídico do que uma adequada solução ao caso concreto (SARMENTO, 2008).

Todavia, após as duas grandes guerras mundiais, a maior complexidade social e o reconhecimento do caráter vinculante das Constituições mostraram as insuficiências do positivismo. A partir daí, surgiu a necessidade de reforçar a concretização dos direitos, por meio da sua constitucionalização e do fortalecimento do Poder Judiciário e das Cortes Constitucionais em face da arbitrariedade do legislador ordinário e dos gestores. Isto propiciou o avanço técnico na construção de normas e maior abertura do sistema científico, por meio de conceitos jurídicos indeterminados, cláusulas gerais e princípios (ZAGREBELSKY, 2011; CANARIS, 2002).

Diante de um crescente intervencionismo estatal em prol dos interesses coletivos, operacionalizava-se a transformação do Estado Liberal em um Estado Social. Tais efeitos foram sentidos no Brasil, 
notadamente, após a Constituição da República Federativa do Brasil de 1988 (BONAVIDES, 2013). Nesta ocasião, a proteção constitucional começou a recair, prioritariamente, sobre os direitos fundamentais sociais à educação, à saúde, à alimentação, ao trabalho, à moradia, ao transporte, à segurança, à previdência social, à proteção à maternidade e à infância e à assistência aos desamparados (art. 60 , CF/88).

No que se refere à saúde, o art. 196 da Constituição Federal impôs ao Estado a responsabilidade por sua proteção e implementação. Entretanto, não somente o Estado, como também a população em geral está imbuída do dever de realização, exigência e fiscalização de políticas sociais e econômicas conducentes à promoção, prevenção, proteção e recuperação da saúde.

Ademais, é importante observar que a prestação do serviço de assistência à saúde não é atividade exclusiva do Estado, consoante previsão do art. 199, caput, da Constituição Federal de 1988: "A assistência à saúde é livre à iniciativa privada". Com efeito, paralelamente ao serviço público, há o serviço privado de saúde, hipótese em que a gestão é privada, cabendo tão somente ao Poder Público a regulamentação, a fiscalização e o controle da atividade de assistência à saúde ${ }^{2}$.

A assistência privada à saúde pode ocorrer de duas formas, mediante a saúde complementar e a saúde suplementar. A saúde complementar está prevista no art. 199, §1ํㅡㄹ da Constituição Federal e nos art. 24 a 26 da Lei Orgânica da Saúde (Lei no 8.080/1990), os quais preveem que o Sistema Único de Saúde - SUS poderá contratar os serviços ofertados pela iniciativa privada, por meio de contratos de direito público ou convênios, quando as disponibilidades do setor público forem insuficientes para garantir os serviços de saúde à população.

Por sua vez, a saúde suplementar é o setor que presta assistência à saúde sem qualquer financiamento público. Os serviços das entidades privadas são financiados pelo pagamento direto do usuário ao prestador dos serviços de saúde ou pela contratação voluntária de operadoras de planos de saúde, que intermedeiam o pagamento dos serviços aos prestadores. A regulação e fiscalização do setor de saúde suplementar ocorrem, respectivamente, por meio da Lei no 9.656/98 e da Agência Nacional de Saúde Suplementar - ANS (SANTOS, 2009). 
Deste modo, o Poder Público exige que as operadoras de planos de saúde, para atuarem no mercado, observem o que está disposto na Lei no 9.656/98 e nas normas da ANS. Partindo desta premissa, verifica-se que o art. 10 da Lei no 9.656/98 e o art. 20, §1º , da Resolução Normativa no 387/15 preveem hipóteses de exclusão de procedimentos e produtos da cobertura dos planos de saúde.

O Poder Judiciário, por outro lado, quando provocado a se manifestar sobre os serviços privados de saúde, em larga escala, decide obrigar as operadoras de planos de saúde a fornecerem quase todo tipo de tratamento aos seus consumidores, até mesmo aqueles não albergados pelo contrato. O Superior Tribunal de Justiça (doravante STJ), inclusive, em 2007, consolidou entendimento no sentido de que "pode até o plano de saúde estabelecer quais doenças estão por ele cobertas, porém não qual dos tipos de tratamento está alcançado para a respectiva cura" (REsp 68.216-SP), conforme noticiado no Informativo no $313^{3}$.

Assentado o contexto em que se insere o presente estudo, tem-se que ele objetiva realizar uma análise hermenêutica das decisões do Superior Tribunal Justiça envolvendo restrição de tratamento por planos de saúde, a fim de observar se o Poder Judiciário esvazia ou não a função reguladora e fiscalizadora da ANS. Merece ser referido, por oportuno, decisão mais recente, de 2017, da Terceira Turma do STJ, no REsp 1.663.141, em que se deu provimento à irresignação de plano de saúde contra decisão que determinara o fornecimento de medicamento importado sem registro na ANVISA. Entendeu-se que determinar tal fornecimento viola o art. 10, V, da Lei 9.656/1998 e o art. 12 da Lei 6.360/1976. Houve interposição de recurso de embargos de divergência, o que poderá levar a Corte a se posicionar sobre o tema e torna ainda mais relevante o exame da questão.

A metodologia de pesquisa, quanto à abordagem ou à natureza do estudo, é do tipo bibliográfico e documental, uma vez que a investigação foi realizada com base em livros, artigos científicos de periódicos nacionais, legislação brasileira e jurisprudência do STJ - com base nas palavras-chave "plano de saúde", "cláusula abusiva", "cobertura", "tratamento" e "restrição" - e dados oficiais publicados na Internet. Por fim, quanto à finalidade, a pesquisa é descritiva e exploratória, porque busca expor o cenário político, jurídico e filosófico em que se encontra 
a atividade interpretativa do direito e investigar se há ativismo judicial em matéria de saúde suplementar.

\section{SAÚDE SUPLEMENTAR NO BRASIL E O PAPEL DA AGÊNCIA NACIONAL DE SAÚDE SUPLEMENTAR}

No Brasil, o setor de assistência privada à saúde surgiu por volta de 1920 e 1930, quando foram instituídas as primeiras organizações previdenciárias e de assistência privada à saúde dos trabalhadores. Registra-se como marco histórico da saúde suplementar o Decreto oㅡ 4.682 (Lei Eloy Chaves), de 24 de janeiro de 1923, que criou as primeiras Caixas de Aposentadoria e Pensões, voltadas aos trabalhadores das estradas de ferro. As Caixas de Aposentadoria e Pensões eram fundos gerenciados e financiados por empregadores e empregados que, além de garantirem aposentadorias e pensões, também pagavam os serviços médicohospitalares aos trabalhadores e seus dependentes (COUTINHO, 2010).

Nos anos de 1930, início da Era Vargas, foram criados os institutos de aposentadoria e pensão para certas categorias profissionais, para as quais se disponibilizavam serviços médico-hospitalares. Por exemplo, o Instituto de Aposentadoria e Pensão dos Marítimos (IAPM) - criado em junho de 1933 -, o Instituto de Aposentadoria e Pensão dos Comerciários (IAPC) - criado em maio de 1934 -, o Instituto de Aposentadoria e Pensão dos Bancários (IAPB) - criado em julho 1934 -, o Instituto de Aposentadoria e Pensão dos Industriários (IAPI) - criado em dezembro de 1936 - e o Instituto de Previdência e Assistência aos Servidores do Estado (IPASE) - criado em fevereiro de 1938.

Entretanto, somente nos anos de 1960 houve o surgimento dos planos de saúde na forma como são conhecidos atualmente. 0 processo de industrialização e de abertura do mercado interno brasileiro para a instalação de empresas estrangeiras fez com que os empregadores sentissem a necessidade de possibilitar o acesso a serviços médicohospitalares aos seus empregados. Diante desta situação, foi criada a medicina de grupo, que consiste no firmamento de contratos coletivos, 
por meio dos quais é oferecida cobertura de serviços de saúde aos trabalhadores das empresas (GOMES, 2016).

Ademais, em 1966, foi editado o Decreto-Lei no 73, responsável por disciplinar os seguros de saúde e criar os serviços de saúde pré-pagos. 0 referido decreto instituiu o Conselho Nacional de Seguros Privados CNSP e a Superintendência de Seguros Privados - SUSEP 4 . A partir daí, os serviços de assistência privada à saúde foram estendidos a qualquer pessoa que pudesse e quisesse contratá-los.

Na década de 1970, surgiu o "movimento da reforma sanitária" face ao modelo assistencial de saúde vigente no Brasil. À época, a Constituição Federal anunciava uma política pública de saúde e o Estado teria a faculdade de efetivá-la ou não. Além disso, o serviço de saúde era prestado pelo Estado apenas àqueles que se encontravam na condição de trabalhador-beneficiário. Assim, o direito fundamental à saúde era tratado como mera norma programática e os serviços de saúde eram prestados a uma restrita parcela da população (SHULZE, 2014). A despeito disto, os efeitos do movimento apenas se fizeram sentir a partir da Constituição Federal de 1988.

Ainda nessa década, a SUSEP autorizou que as seguradoras de planos de saúde disponibilizassem um número maior de serviços, por meio de uma rede credenciada de profissionais de saúde, hospitais, clínicas, diagnósticos e tratamentos. A consequência disto foi a expansão do setor de saúde privada, pelo crescimento da comercialização de planos individuais e familiares, bem como pela inserção no mercado brasileiro de grandes operadoras (GONÇALVES, 2016).

No final dos anos 80, se instaurou uma nova ordem jurídica no Brasil, com a promulgação da Constituição Federal, em 05 de outubro de 1988. A Constituição dá um grande passo em matéria de direito à saúde, exigindo-se do Estado a adoção de políticas públicas de saúde a todas as pessoas, independente de contribuição à Seguridade Social. Além disso, o art. 199, caput, da Constituição, recepcionou a saúde suplementar.

Todavia, durante os dez primeiros anos da Constituição Federal, o legislador infraconstitucional quedou-se inerte quanto à regulação específica para os planos de saúde, sendo o Decreto-Lei no 73/66 o único regramento previsto para a saúde suplementar. Até que, em 03 
de junho de 1998, foi aprovada a Lei no 9.656, mais conhecida como Lei dos Planos de Saúde.

Quando da entrada em vigor da Lei dos Planos de Saúde, a competência para regular a atividade econômica das operadoras de planos de saúde era do Ministério da Fazenda, por meio do Conselho Nacional de Seguros Privados - CNSP e da Superintendência de Seguros Privados - SUSEP, e a competência de regular a assistência privada à saúde foi conferida ao Ministério da Saúde, mediante a atuação do Conselho de Saúde Suplementar - CONSU e da Secretaria de Assistência à Saúde - SAS, por meio do Departamento de Assistência à Saúde - DESAS.

A Medida Provisória no 1908-18/99, por sua vez, unificou o quadro regulatório. 0 Ministério da Saúde passou a regular tanto a atividade econômica, quanto a assistência à saúde do setor de saúde suplementar, por meio do CONSU e da SAS/DESAS. Pois, o CONSU absorveu as atribuições do CNSP, ao passo que a SAS/DESAS tomou para si as atribuições da SUSEP (GOMES, 2016).

Posteriormente, em 25 de novembro de 1999, com a edição da Medida Provisória no 1.928, reeditada pela Medida Provisória no 20122 e convertida na Lei no 9.961, de 28 de janeiro de 2000, foi criada a Agência Nacional de Saúde Suplementar - ANS, uma autarquia de regime especial $^{5}$, vinculada ao Ministério da Saúde, com atuação em todo o território nacional.

Neste momento, a ANS absorvia as atribuições da SAS/DESAS, passando a competência para regular a atividade econômica e de assistência à saúde dos planos à ANS e ao CONSU. 0 art. $4^{\circ}$ da Lei $\mathrm{n}^{0}$ 9.961/00 descreve as atribuições da ANS, dentre elas a de elaborar o rol de procedimentos e eventos em saúde, que constituirão referência básica para os fins do disposto na Lei no 9.656/98, e suas excepcionalidades ${ }^{6}$.

Além disso, a Lei no 9.656/98, no seu art. 1ํo, §1ํㅡㄹ estabelece que as operadoras de planos de saúde, bem como "qualquer modalidade de produto, serviço e contrato que apresente, além da garantia de cobertura financeira de riscos de assistência médica, hospitalar e odontológica, outras características que o diferencie de atividade exclusivamente financeira", estão subordinados às normas e à fiscalização da ANS. Há, é certo, a polêmica acerca da aplicação da Lei 9.656/98 a contratos 
assinados antes de sua vigência. O STF, porém, em decisão de 2014, proferida na ADI 1931-MC ED ${ }^{7}$, entendeu que mesmo no caso de contratos anteriores é necessário "proteger a parte hipossuficiente da relação jurídica”. Aplicam-se, no caso, para os contratos anteriores à Lei 9.656/98, o Código de Defesa do Consumidor e, antes mesmo deste, também os princípios gerais de direito, como a boa-fé, a proteção da parte hipossuficiente da relação jurídica e a vedação ao abuso de direito, "descabendo falar em direito adquirido à atuação em mercado ausente de fiscalização do poder público" (trechos transcritos do voto do Ministro Marco Aurélio).

Diante do exposto, verifica-se que, no Brasil, o setor de saúde suplementar se sujeita, ao menos em parte, aos ditames da Lei no 9.656/98 e à regulamentação e fiscalização da ANS. No entanto, questiona-se: uma vez que os contratos entre as operadoras de saúde e seus clientes são aprovados pela ANS, é possível por meio de decisão judicial declarar a ilegalidade de cláusulas contratuais ali preteritamente pactuadas?

Faz-se necessário, portanto, analisar as decisões judiciais envolvendo restrição (ou negativa) de tratamento por planos de saúde.

\section{A RESTRIÇÃO DE TRATAMENTO POR PLANOS DE SAÚDE E A JUDICIALIZAÇÃO DA SAÚDE SUPLEMENTAR}

Cada vez mais, os consumidores recorrem ao Poder Judiciário, em busca de respostas satisfatórias às pretensões por serviços de assistência privada à saúde. Segundo, pesquisa realizada pela Unimed Belo Horizonte Cooperativa de Trabalho Médico Ltda., de 2005 a 2009, houve um aumento de, aproximadamente, $67 \%$ do número de acórdãos no Tribunal de Justiça de Minas Gerais sobre pedidos assistenciais ajuizados contra as operadoras de planos de saúde ${ }^{8}$. Tal fenômeno é denominado “judicialização” da saúde suplementar (SARLET; SAAVEDRA, 2017).

Thiago Penido Martins (2016) informa que a maior parte das demandas judiciais envolvendo as operadoras de planos de saúde e seus beneficiários versam sobre o pedido de custeio de procedimentos médico-hospitalares não cobertos pelos contratos de planos de saúde. 
A partir daí, levanta-se a seguinte questão jurídica: as operadoras de planos privados de assistência à saúde são obrigadas a cobrir serviços não albergados pelos contratos celebrados entre operadora e consumidor?

Como visto, o art. 4ํㅡㄴ III, da Lei no 9.961/00 atribuiu à ANS competência de elaborar o rol básico de procedimentos e eventos em saúde, para cobertura assistencial mínima nos planos privados de assistência à saúde. Até a presente data, este rol é regulado pela Resolução Normativa no 387, de 28 de outubro de 2015. Não obstante, a referida resolução, em seu art. $20, \S 1$ , estabeleceu a possibilidade de exclusão de procedimentos assistenciais da cobertura dos planos de saúde, in verbis:

São permitidas as seguintes exclusões assistenciais:

I - tratamento clínico ou cirúrgico experimental, isto é, aquele que:

a) emprega medicamentos, produtos para a saúde ou técnicas não registrados/não regularizados no país;

b) é considerado experimental pelo Conselho Federal de Medicina - CFM ou pelo Conselho Federal de Odontologia - CFO; ou

c) não possui as indicações descritas na bula/manual registrado na ANVISA (uso off-label).

II - procedimentos clínicos ou cirúrgicos para fins estéticos, bem como órteses e próteses para o mesmo fim, ou seja, aqueles que não visam restauração parcial ou total da função de órgão ou parte do corpo humano lesionada, seja por enfermidade, traumatismo ou anomalia congênita;

III - inseminação artificial, entendida como técnica de reprodução assistida que inclui a manipulação de oócitos e esperma para alcançar a fertilização, por meio de injeções de esperma intracitoplasmáticas, transferência intrafalopiana de gameta, doação de oócitos, indução da ovulação, concepção póstuma, recuperação espermática ou transferência intratubária do zigoto, entre outras técnicas;

IV - tratamento de rejuvenescimento ou de emagrecimento com finalidade estética, assim como em spas, clínicas de repouso e estâncias hidrominerais; $\mathrm{V}$ - fornecimento de medicamentos e produtos para a saúde importados não nacionalizados, isto é, aqueles produzidos fora do território nacional e sem registro vigente na ANVISA;

VI - fornecimento de medicamentos para tratamento domiciliar, isto é, aqueles prescritos pelo médico assistente para a administração em ambiente externo ao de unidade de saúde, com exceção dos medicamentos previstos nos incisos X e XI do art. 21 desta RN e, ressalvando o disposto no artigo 14 desta resolução normativa; 
VII - fornecimento de próteses, órteses e seus acessórios não ligados ao ato cirúrgico;

VIII - tratamentos ilícitos ou antiéticos, assim definidos sob o aspecto médico, ou não reconhecidos pelas autoridades competentes;

IX - casos de cataclismos, guerras e comoções internas, quando declarados pela autoridade competente; e

$\mathrm{X}$ - estabelecimentos para acolhimento de idosos e internações que não necessitem de cuidados médicos em ambiente hospitalar.

Diante desta norma restritiva de procedimentos, selecionaram-se todas as demandas envolvendo cláusula de exclusão de procedimentos e tratamentos médico-hospitalares julgadas pelo colegiado do STJ em 2016. Os processos podem ser visualizados no sítio eletrônico "http://stj.jus. br/SCON/". Para abreviar a pesquisa, utilizaram-se os vocábulos "plano de saúde", "cláusula abusiva", "cobertura", "tratamento" e "restrição" no campo "pesquisa livre", bem assim, elegeu-se o intervalo de tempo entre 01 de janeiro de 2016 e 31 de dezembro de 2016, residindo o foco do estudo nos "acórdãos" do referido tribunal. Feito este procedimento, chegou-se ao resultado de três acórdãos. Todos os três acórdãos foram julgados desfavoráveis às operadoras de planos de saúde. Passa-se à análise das decisões no AgRg no AREsp 590457/SE, AgInt no AREsp 900021/MG e AgInt no AREsp 934017/DF.

No Agravo Regimental no Agravo em Recurso Especial 590457/ SE, sob a relatoria do Ministro Raul Araújo, da Quarta Turma, julgado em 08 de março de 2016, a agravada, paciente idosa, é portadora de hidrocefalia e necessitava de cirurgia de "derivação ventrículo peritoneal". 0 agravante, operadora de planos de saúde, autorizou o procedimento cirúrgico, mas negou o material solicitado pelo médico. 0 plano de saúde alegou que não recusou a cobertura do produto solicitado, mas tão somente, forneceu à autora material em conformidade com o contrato de plano de saúde pactuado entre as partes.

Por sua vez, a Quarta Turma do STJ reputou abusiva a cláusula restritiva de direito, que exclua da cobertura dos planos de saúde órteses e próteses de qualquer natureza e materiais importados ou não, diretamente ligados a procedimentos cirúrgicos, quando se mostrarem imprescindíveis para garantir a saúde e, em alguns casos, a vida do 
segurado. Assim, a Quarta Turma do STJ, por unanimidade, negou provimento ao agravo regimental, mantendo a decisão do Tribunal de Justiça do Estado de Sergipe. Ou seja, sustentou a obrigação da operadora em fornecer o material solicitado pelo médico e a indenização por danos morais em $\mathrm{R} \$ 10.000,00$ (dez mil reais) contra a operadora de planos de saúde.

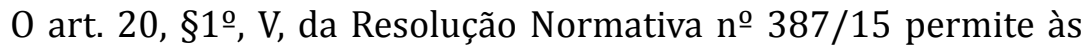
operadoras a exclusão de fornecimento de produtos para a saúde importados, produzidos fora do território nacional e sem registro vigente na ANVISA. Ao passo que, reiterado entendimento do STJ é no sentido de ser indiferente se o material solicitado pelo médico é ou não importado:

Ainda que se admita a possibilidade do contrato de plano de saúde conter cláusulas que limitem direitos do consumidor, desde que estas estejam redigidas com destaque, permitindo sua imediata e fácil compreensão, nos termos do $§ 4^{\circ}$ do artigo 54 do CDC, mostra-se abusiva a cláusula restritiva de direito que prevê o não custeio de prótese, imprescindível para o êxito do procedimento cirúrgico coberto pelo plano, sendo indiferente, para tanto, se referido material é ou não importado; II - Recurso provido. (REsp 1.046.355/ RJ, Relator o Ministro MASSAMI UYEDA, DJe de 5.8.2008) (grifos nosso)

Com efeito, o STJ ignorou a prévia regulação da ANS. É certo que, em 2017, foi proferida decisão em sentido contrário, pela Terceira Turma do STJ, no REsp 1.663.141. Mas tal decisão ainda não transitou em julgado, o que pode constituir uma oportunidade para a Corte mudar sua jurisprudência.

A decisão proferida no Agravo Interno no Agravo em Recurso Especial 900021/MG também desconsidera a regulação efetuada pela ANS. 0 AgInt no AREsp 900.021/MG, sob a relatoria do Ministro Marco Aurélio Bellizze, da Terceira Turma, julgado em 18 de agosto de 2016, trouxe o caso do autor - agravado - que ingressou com ação contra a operadora de planos de saúde, pleiteando o ressarcimento da quantia despendida com o medicamento "Xeloda", necessário ao tratamento do câncer. A operadora - agravante - havia se negado a cobrir as despesas com o referido medicamento, porque o contrato firmado entre as partes exclui, expressamente, a cobertura de medicamentos orais e de uso 
domiciliar, conforme autorização prevista no art. 20, §1ํㅡ, VI, da Resolução Normativa no 387/15.

Por outro lado, a Terceira Turma do STJ reconheceu a obrigatoriedade da operadora de custear a medicação, por meio dos seguintes motivos: a) o contrato prevê cobertura para o câncer; b) há a necessidade do uso do medicamento no tratamento do câncer; e c) o contrato prevê cobertura para procedimento de quimioterapia e, por interpretação extensiva, esta medicação faz parte do tratamento. Deste modo, a decisão considerou abusiva a cláusula contratual que exclui tratamento ou procedimento médico-hospitalar que é essencial para garantir a saúde e a vida do segurado. Finalmente, a Terceira Turma do STJ amparou-se no seu precedente judicial: o plano de saúde pode estabelecer as doenças que terão cobertura, mas não o tipo de terapêutica utilizado para o tratamento de cada uma delas, pois tal competência seria do profissional habilitado na busca da cura (Informativo no 313 do STJ). Portanto, a Terceira Turma do STJ, por unanimidade, negou provimento ao agravo interno impetrado pela operadora.

Outrossim, no Agravo Interno no Agravo em Recurso Especial 934017/DF, sob a relatoria do Ministro Raul Araújo, da Quarta Turma, julgado em 04 de outubro de 2016, analisou-se o caso da seguradafalecida (espólio) - agravada - que necessitava de tratamento cirúrgico, para o implante percutâneo de válvula aórtica indicada pelo médico cardiologista. A operadora - agravante -, por sua vez, negou o custeio do referido tratamento, com fulcro na cláusula 5.1 do contrato de assistência privada à saúde, firmado pelas partes, a qual excluía, expressamente, a cobertura de "aparelhos ortopédicos e para a substituição ou complementação de função, bem com próteses e órteses de qualquer natureza, incluindo marca passo cardíaco".

A Quarta Turma do STJ, mais uma vez, entendeu abusiva a cláusula limitadora de procedimentos e tratamentos relacionados às doenças contratualmente cobertas, ratificando, assim, a decisão do Tribunal de Justiça do Distrito Federal e dos Territórios que determinou o reembolso integral das despesas com o tratamento pago pela segurada-falecida (espólio) e a manutenção dos danos morais arbitrados em $\mathrm{R} \$ 3.000,00$ (três mil reais) contra a operadora de planos de saúde. Desta feita, a 
Quarta Turma, por unanimidade, negou provimento ao agravo interno impetrado pela operadora de planos de saúde.

Verificou-se que o precedente do STJ - que considera abusivas todas as cláusulas contratuais dos planos de saúde que visam a restringir procedimentos e tratamentos médico-hospitalares de doenças contratualmente cobertas - tem por base os direitos fundamentais à vida e à saúde do consumidor. Ocorre que o referido tribunal cita esses direitos fundamentais sem tecer maiores considerações. Neste diapasão, importantes são as observações de Daniel Sarmento (2008, p. 250):

Já na jurisprudência brasileira ocorre um fenômeno de certa forma curioso. Não são escassas as decisões judicias utilizando diretamente os direitos fundamentais para dirimir conflitos de caráter privado. Porém, com raras exceções, estes julgamentos não são precedidos de nenhuma fundamentação teórica que dê lastro à aplicação do preceito constitucional ao litígio entre particulares. Na verdade, somente agora vem encontrando eco nos nossos pretórios a fértil discussão sobre os condicionamentos e limites para aplicação dos direitos humanos na esfera privada.

A restrição de tratamentos assistenciais por planos de saúde, legalmente autorizados pela ANS, é vencida pelo Poder Judiciário, o qual vem obrigando as operadoras de saúde a fornecerem quase todo tipo de tratamento aos seus consumidores, em detrimento: a) do equilíbrio contratual; b) da manutenção do que fora livremente contratado entre as partes (autonomia privada); e c) do caráter social do direito à saúde. Como resultado, o recurso ao Poder Judiciário tornou-se uma constante saída individual.

Sendo assim, fez-se necessário impor critérios jurídicos à atividade do Poder Judiciário. Para tanto, passa-se, no tópico seguinte, a discorrer sobre a nova hermenêutica constitucional e a Chevron Doctrine, a fim de compreender o fenômeno do ativismo judicial e averiguar a possibilidade de impor limites à atividade jurisdicional. 


\section{NOVA HERMENÊUTICA CONSTITUCIONAL E A CHEVRON DOCTRINE}

A mudança do modelo de Estado Liberal em Estado Social provocou uma nova ordem político-jurídica e, consequentemente, uma nova hermenêutica (BARROSO, 2002). As transformações sobre a teoria do direito foram profundas, por isso, antes de abordar acerca da nova hermenêutica constitucional, é necessário conhecer as razões históricas, políticas, jurídicas e filosóficas que provocaram essas alterações.

Inicialmente, no século XIX, o Estado Liberal, consolidado depois das conquistas revolucionárias na França, considerava a lei codificada completa. Nascia, assim, a teoria da plenitude da lei e o positivismo jurídico, limitando a interpretação do texto da lei ao plano gramatical (ou literal). 0 juiz era visto como mero aplicador das leis e as suas sentenças estavam sujeitas a invalidação por meio do exame da Corte de Cassação, composto por membros do Parlamento (SARMENTO, 2008).

No século XX, passou-se a reconhecer uma maior liberdade na atuação do Poder Judiciário, para colmatar as lacunas identificadas na lei positiva (OLIVEIRA, 2017). Assim, cientistas e aplicadores do direito passaram a reconhecer a incompletude da lei e a provisoriedade do conhecimento científico (ALEXY, 2014; CANARIS, 2002; DWORKIN, 2010; MÜLLER, 2009). A partir daí, surgem novas formas de pensar o direito e a sua aplicação.

Herbert Hart, representante do positivismo jurídico, iniciou a difusão da autonomia do julgador. Para Hart (2009), o direito seria um sistema composto exclusivamente de regras. Até aí, mantinha-se o pensamento "positivista" do Estado Liberal. O que o diferencia dos demais autores positivistas da época é a possibilidade do julgador (ou aplicador) poder criar direito novo. Isso se daria quando o juiz, diante de um caso difícil (hard case), não consegue identificar nenhuma regra aplicável, a não ser por meio do recurso à discricionariedade judicial (HART, 2009; SILVA, 2003).

O conceito de discricionariedade foi desenvolvido por Hart (2009) na sua obra "O conceito de direito", definindo-o como um âmbito de liberdade alcançado pelo julgador em casos de inexistência de critérios 
jurídicos legítimos para orientar a sua decisão. Nesta situação, o juiz teria um alto grau de liberdade para decidir.

A teoria de Ronald Dworkin, por sua vez, surgiu em oposição ao positivismo jurídico, especialmente contra a teoria do direito de seu mestre Herbert Hart. Neste momento, emerge o pós-positivismo. Segundo Dworkin, o sistema jurídico não é composto exclusivamente de regras, e sim de regras e princípios. Os princípios seriam os critérios jurídicos legítimos a serem utilizados pelos julgadores no momento que o juiz precisasse resolver um caso difícil. Portanto, por meio da argumentação jurídica embasada nos general principles of law, os juízes decidiriam o caso complexo e evitariam decisões arbitrárias (DWORKIN, 2010).

Além disso, Dworkin (2010) defende que a distinção entre regras e princípios é de natureza qualitativa. Deste modo, a primeira diferença que se faz necessária explanar é a que diz respeito à forma que essas normas são aplicadas. As regras são aplicadas no tudo ou nada, ou seja, em sua inteireza. Isso significa que, quando a hipótese de incidência de uma regra é preenchida, ou é a regra válida e a consequência normativa deve ser aceita, ou ela é inválida e assim, será expurgada do ordenamento jurídico. Ao passo que, os princípios são aplicados de modo gradual mais ou menos. Isso quer dizer que os princípios não determinam absolutamente a decisão, mas apenas contêm fundamentos, os quais devem ser conjugados com outros fundamentos provenientes de outros princípios (DWORKIN, 2010).

Outra distinção entre regras e princípios é quanto ao relacionamento normativo. Um conflito de regras é solucionado pela declaração de invalidade de uma das regras. Enquanto que, a colisão de princípios é resolvida mediante o sopesamento de princípios, sem que perca sua validade. Sendo assim, o conflito entre regras ocorre na dimensão da validade, já a colisão entre princípios ocorre na dimensão de peso (DWORKIN, 2010).

Robert Alexy parte do mesmo pressuposto de Dworkin: a distinção entre regras e princípios é qualitativa. Sua contribuição foi precisar algumas ideias básicas da estrutura das normas - distinção entre regras e princípios - e desenvolver a ideia de princípio como mandamento de otimização. Ressalte-se que, na obra "Teoria dos direitos fundamentais", 
antes de analisar a estrutura das normas, Alexy (2014) conceitua a norma de direito fundamental. A norma é o significado de um enunciado normativo (ou deôntico), que expressa algo que é devido, proibido ou permitido (dever-ser). E, completa que normas de direitos fundamentais são as normas diretamente expressas pelas disposições da Constituição Federal vigente.

Então, a norma de direito fundamental pode ser uma regra ou um princípio. Para Alexy (2014), a diferença entre regras e princípios é mais nítida nos casos de conflito entre regras e colisão entre princípios. 0 conflito entre regras somente pode ser solucionado por meio da introdução de uma cláusula de exceção na regra que elimine o conflito, ou mediante a invalidade de uma das regras. Já a colisão entre princípios é resolvida pela precedência de um princípio em face de outro, sob determinadas condições. 0 resultado do sopesamento entre princípios é a regra de precedência. Verifica-se que as decisões sobre direitos fundamentais pressupõem a identificação de uma regra (mandamento definitivo). Apesar disto, ressalte-se que os princípios nunca são razões definitivas.

Sendo assim, Alexy (2014, p. 103-104) aponta que os princípios, na verdade, são normas que estabelecem que "algo seja realizado na maior medida possível dentro das possibilidades jurídicas e fáticas existentes. Nesse sentido, eles não contêm um mandamento definitivo, mas apenas prima facie". Por isso, os princípios são chamados de mandamentos de otimização.

Exposta a definição e estrutura da norma de direito fundamental, é necessário mencionar que o objetivo da teoria dos direitos fundamentais, de Alexy, é demonstrar a importância de a decisão judicial ser racionalmente fundamentada em todos os casos, inclusive, naqueles que envolvem questões socialmente relevantes e que foram deixadas em aberto pelo vasto material normativo previamente determinado (sistema aberto).

É certo que se vive um período para além de um positivismo estritamente legalista, onde se incluem as relações entre valores, princípios e regras, aspectos da chamada nova hermenêutica constitucional (BARROSO, 2002; BONAVIDES, 2013) e teoria dos direitos fundamentais 
(ALEXY, 2014; DWORKIN, 2010). Assim, a resposta para cada controvérsia não é mais encontrada, exclusivamente, na regra do artigo de lei, mas também nos princípios.

Todavia, Juliana Campos e Felipe Albuquerque (2015) alertam para o fato de que a nova hermenêutica constitucional supervaloriza os princípios como norma-base da ordem constitucional, estabelecendo, assim, uma hierarquia questionável entre regras e princípios e o esgotamento entre as funções legislativa e normativo-decisória. Marcelo Neves (2013) também adverta que a notável prática jurídica pautada no abuso dos princípios torna o Direito manipulável pelas mais diversas pressões/opiniões sociais. Assim, ao invés do Poder Judiciário promover a justiça, ele levaria ao abandono de valores básicos, como racionalidade, universidade e igualdade, em benefício de interesses individuais (PÉREZ LUÑO, 2014).

Além disso, no Estado Democrático de Direito, não é permitido cumprir a lei só quando interessa, até porque, o cumprimento da lei (dever-ser) é uma das características do direito (VASCONCELOS, 2006) e uma das exigências da democracia (STRECK, 2014). Neste sentido, Pérez Luño (2014, p. 140) sugere que, diante de legislação obsoleta, é aconselhável "optar por um programa de reabilitação de legislação, de acordo com as exigências das mudanças jurídicas no presente, em vez de renunciar às pressas ao papel que as leis têm desempenhado e ainda cabe a elas como garantia cidadã nas sociedades democráticas".

O cumprimento da lei não pode ser visto sempre como uma postura positivista. Lenio Streck (2014) desmistifica esta crença, quando afirma que apegar-se à letra da lei pode ser ou não uma atitude positivista, bem como não prender-se à vontade da lei pode ser uma atitude positivista ou antipositivista. Pois, o que sempre caracterizou o positivismo jurídico é o fato de defender a separação entre direito e moral (metafísica) e a ausência de uma teoria da interpretação (KELSEN, 2006), que causava uma aposta na discricionariedade (HART, 2009).

A discricionariedade, na realidade brasileira, pode resultar no ativismo judicial. 0 ativismo judicial é, como visto nas decisões do STJ, uma intromissão do Poder Judiciário nas relações privadas (autonomia privada), na função legislativa do Poder Legislativo e, até mesmo, 
na interpretação de uma lei pelas agências reguladoras. Para frear o ativismo judicial, Juraci Mourão Lopes Filho (2010, p. 4484) propõe que "a atividade jurisdicional deve, então, respeitar a decisão legislativa e jamais substituir a ponderação abstrata realizada e inserida em lei”. Deste modo, para o referido autor, na ausência de lei, é facultado ao juiz aplicar diretamente os direitos fundamentais envolvidos (princípios), para preencher a "lacuna" da lei. Já, após a edição de lei, a atividade jurisdicional se limita a exercer um controle de constitucionalidade, mediante um juízo de ponderação concreto, jamais abstrato.

Ainda acerca dos limites à atividade jurisdicional, Eduardo Rocha Dias (2008, p. 289) assevera que o aplicador do direito deveria "buscar apenas a solução mais razoável, ou mais plausível, verossímil ou defensável" para cada situação jurídica. Neste diapasão, há doutrina condizente a essa assertiva, qual seja a Chevron Doctrine. Segundo Eduardo Fortunato Bim (2012, p. 134), "um ponto fundamental da doutrina Chevron é o de que por ela não se averigua qual é a melhor interpretação do significado da norma, mas apenas uma razoável, vedando-se leituras arbitrárias".

A Chevron Doctrine (ou judicial deference) foi elaborada pela Suprema Corte estadunidense, em 1983. De acordo com esta doutrina, o Poder Judiciário deve respeitar a interpretação das leis feita pela Administração Pública, podendo intervir apenas em casos teratológicos (DIAS, 2010; BIM, 2012). Se os Estados Unidos da América, país de sistema jurídico inserido no common law, impõe respeito às interpretações das agências reguladoras, o que se espera do Brasil, um país de sistema jurídico civil law? Sem dúvidas, no Brasil, deveria exigir-se deferência judicial às resoluções da ANS, a menos que sejam ilegais ou inconstitucionais.

Adotando-se a Chevron Doctrine à estrutura jurídica brasileira, o art. 10, caput, da Lei no 9.656/98 e o art. 20, §1ํㅡ, da Resolução Normativa no 387 da ANS precisam ser observados pelo Poder Judiciário nos casos concretos. Isso, porque ambos estão em vigor e as decisões do STJ em nenhum momento reconheceram a inconstitucionalidade dessas normas restritivas de tratamentos por plano de saúde. Portanto, se o STJ afastar norma preexistente, sem declarar a sua inconstitucionalidade, estar-se-á diante de notório ativismo judicial em matéria de saúde suplementar. 
Sob outra perspectiva, deve-se apontar para a necessidade de reconhecer limites às capacidades institucionais do Judiciário. Cass Sunstein e Adrian Vermeule (2002) defendem que o tema da interpretação no direito, em especial a maior ou menor deferência aos sentidos textuais de normas jurídicas, deve levar em conta aspectos institucionais. Dentre tais aspectos, apontam a confiabilidade dos juízes, em especial se detêm conhecimentos específicos relativos à legislação que pretendem aplicar, e os efeitos sistêmicos que suas decisões podem vir a acarretar. Ou seja, podem juízes generalistas adotar interpretações mais amplas de textos relativos a temas específicos que não dominam, como, por exemplo, os referentes à saúde? Ou é melhor que adotem interpretações mais restritas e formalistas? Podem os juízes avaliar as consequências que suas decisões acarretam no sistema de saúde e nos orçamentos de operadoras de planos de saúde? Em que medida os magistrados podem adotar soluções que ignoram o teor textual das regulamentações em vigor? São, sem dúvida, questões relevantes que devem ser enfrentadas pelo Judiciário.

\section{CONSIDERAÇÕES FINAIS}

Diante da tentativa de superação do modelo primitivo do positivismo jurídico pelas teorias dos direitos fundamentais, surgiu a Nova Hermenêutica Constitucional, cujas características percebidas foram: a) o reconhecimento da existência de duas estruturas de normas de direitos fundamentais, diferencias pelo modo de aplicação e pelo relacionamento normativo, quais sejam: as regras e os princípios; b) o uso da técnica do sopesamento entre os princípios para a solução de colisão de normas de direitos fundamentais: $\left(\mathrm{p}^{1} \mathrm{P} \mathrm{p}^{2}\right) \mathrm{C}$; e c) o uso abusivo dos princípios.

No Brasil, o reconhecimento da força vinculante dos princípios foi proclamado a partir da Constituição Federal de 1988 (art. 5ํe seguintes). A partir daí, o uso dos princípios e o seu sopesamento na solução de conflitos tornaram-se uma constante. Esta afirmação pode ser apreendida por meio do exame das decisões do STJ, as quais supervalorizaram os direitos fundamentais à saúde e à vida - na estrutura de princípios -, em detrimento da autonomia privada ou do pacta sunt 
servanda (força obrigatória dos contratos). Deste modo, o STJ afastou as cláusulas contratuais restritivas de tratamentos, sem, contudo, declarar a inconstitucionalidade do art. 10, caput, da Lei no 9.656/98 e do art. 20, §1ํㅜ , da Resolução Normativa no 387 da ANS, que autorizam tal limitação.

Não se está a defender que os contratos de assistência privada à saúde não possam falhar, nem que a autonomia privada está acima dos direitos à saúde e à vida. Todavia, a prática jurisdicional contemporânea (ativismo judicial), acompanhado do elevado número de julgados (judicialização), podem indicar falta de comprometimento judicial com a sustentabilidade do setor privado de saúde e, consequentemente, com a sociedade brasileira, que depende dos planos, para maior assistência à saúde e redução da demanda no SUS.

A intenção dos autores pós-positivistas (Dworkin e Alexy) era dar o mesmo valor normativo das regras aos princípios. Porém, ocorreu o inesperado, a supervalorização dos princípios e o descrédito às regras. Este fato, sem dúvida, esgota a dicotomia entre a função legislativa, do Poder Legislativo, e a função normativo-decisória, do Poder Judiciário. Em outras palavras, o Poder Judiciário usurpa a função primária do Poder Legislativo, esvaziando a competência do órgão legislativo.

Além disso, o emprego desarrazoado e desproporcional dos princípios pelo Poder Judiciário pode esvaziar a função reguladora e fiscalizadora das agências reguladoras, como se verificou nas decisões do AgRg no AREsp 590457/SE, AgInt no AREsp 900021/MG e AgInt no AREsp 934017/DF, as quais consideraram abusivas as cláusulas contratuais que excluem produto, tratamento e procedimento médicohospitalares que são essenciais para garantir a saúde e a vida do segurado.

É certo que, os recursos para custeio dos serviços de saúde privado são escassos. Deste modo, a Lei dos Planos de Saúde e a Resolução Normativa no 387 autorizaram às operadoras de planos de saúde limitar a oferta de determinados materiais, tratamentos e procedimentos médicohospitalares e cirúrgicos, a fim de priorizar outros tratamentos, que se apresentam mais necessários aos seus consumidores.

Diante do exposto, a nova forma de pensar e aplicar o Direito, baseado na linguagem, precisa de limites. 0 constitucionalismo dos direitos fundamentais não pode repetir os equívocos do positivismo 
de Herbert Hart, proporcionando discricionariedade interpretativa. É necessário repensar o papel do Poder Judiciário no Brasil e impor limites à sua atividade interpretativa de forma a respeitar a ordem jurídica vigente e a separação dos poderes.

Para tanto, a doutrina norte-americana Chevron sugere importante limite à interpretação do fenômeno jurídico pelo Poder Judiciário, que é o dever do julgador respeitar a interpretação das leis feita pela Administração Pública (incluindo aí as agências reguladoras), podendo intervir somente nos casos em que a interpretação administrativa ofenda a legalidade ou a Constituição de forma direta.

Sob a ótica da doutrina Chevron, o art. 20, §1ํㅡ, da Resolução Normativa $\mathrm{n}^{0} 387 / 15$, que autoriza a restrição de tratamentos por planos de saúde, é a interpretação administrativa do art. 10, caput, da Lei $\mathrm{n}^{\underline{0}}$ 9.656/98. A manutenção econômico-financeira do setor privado de saúde depende dessa liberdade de restrição de tratamentos (rol taxativo), que dará ensejo a várias ofertas diferentes de cobertura, para escolha do consumidor. Senão, inviabilizarão contratos de saúde a preço acessível, que levará à retração ou, pior, ao fechamento o mercado de saúde suplementar, superlotando os postos de saúde, hospitais e laboratórios públicos ou conveniados com o SUS, que, hoje, já mal conseguem atender à demanda que depende da saúde pública.

Desta feita, não resta dúvida de que o papel do magistrado deve estar pautado no exame da legislação vigente, no sopesamento dos princípios, quando necessário, bem como na análise da situação concreta de um modo macro (universal), e não micro (individualizado) - como está ocorrendo -, para que se leve em consideração as consequências sociais, econômicas e culturais que suas decisões podem causar à coletividade brasileira. 


\section{NOTAS}

10 presente artigo é fruto de pesquisa realizada com apoio da Fundação Cearense de Apoio ao Desenvolvimento Científico e Tecnológico (FUNCAP), com bolsa de formação acadêmica na modalidade mestrado acadêmico.

2 AConstituição Federal, ao reconhecer a "relevância pública" dos serviços de saúde, resguardou o dever do Estado de regulá-los totalmente, conforme estabelece o seu art. 197: "São de relevância pública as ações e serviços de saúde, cabendo ao Poder Público dispor, nos termos da lei, sobre sua regulamentação, fiscalização e controle, devendo sua execução ser feita diretamente ou através de terceiros e, também, por pessoa física ou jurídica de direito privado".

30 texto constante do Informativo no 313 do Superior Tribunal de Justiça é o seguinte: Pode até o plano de saúde estabelecer quais doenças estão por ele cobertas, porém não qual dos tipos de tratamento está alcançado para a respectiva cura. Se cobre a cirurgia cardíaca, não pode vetar o uso de stend; se coberta a de próstata, não pode impedir o uso do esfíncter artificial necessário ao controle da micção. Tal não se pode dar também com o câncer. Se essa patologia está coberta, inviável o veto à quimioterapia ao fundamento de que seria apenas uma das alternativas à cura da doença. 0 empeço a que o consumidor receba o tratamento mais moderno no momento em que instalada a doença coberta revela a abusividade da cláusula impeditiva que põe em risco a vida do consumidor (REsp 668.216-SP, Rel. Min. Carlos Alberto Menezes Direito, 3른 Turma, julgado em 15/03/2007).

4 Decreto-lei no 73/66. Art. 2 0 contrôle do Estado se exercerá pelos órgãos instituídos neste Decreto-lei, no interêsse dos segurados e beneficiários dos contratos de seguro. [...] Art. $8^{\circ}$ Fica instituído o Sistema Nacional de Seguros Privados, regulado pelo presente Decreto-lei e constituído: a) do Conselho Nacional de Seguros Privados - CNSP; b) da Superintendência de Seguros Privados - SUSEP; [...].

5 Lei no 9.961/00. Art. 1o Parágrafo único. A natureza de autarquia especial conferida à ANS é caracterizada por autonomia administrativa, financeira, patrimonial e de gestão de recursos humanos, autonomia nas suas decisões técnicas e mandato fixo de seus dirigentes.

6 Refere-se ao art. 4º, III, da Lei 9.961/00. Existem outras competências da ANS no art. $4^{\circ}$ da Lei 9.961/00, porém, em razão do estudo se restringir aos tratamentos excluídos da cobertura dos planos de saúde, foi descrita apenas esta competência.

7 DJe no 228, de 19 de novembro de 2014.

8 Referida pesquisa, disponível na obra "Judicialização da saúde suplementar", da Unimed - BH, pode ser visualizada no site: <http://arquivos.integrawebsites.com.br/7942/ef2781c2db440b38ee032b23ed5901bc.pdf>. Acesso em: 11 jun. 2017

\section{REFERÊNCIAS}

ALEXY, Robert. Teoria dos direitos fundamentais. Tradução de Virgílio Afonso da Silva. 2. ed. São Paulo: Malheiros editores, 2014.

BARROSO, Luís Roberto. Fundamentos teóricos e filosóficos do novo direito constitucional brasileiro. Direito e democracia: revista de ciências jurídicas, São Paulo 3.2 (2002): 345-384.

BIM, Eduardo Fortunato. Divergências científicas e metodológicas no direito público e no ambiental. Revista de Informação Legislativa, Brasília, ano 49, n. 193, p. 125-139, jan./mar. 2012. 
BONAVIDES, Paulo. Curso de Direito Constitucional. 28. ed. São Paulo: Malheiros Editores, 2013.

BRASIL. Agência Nacional de Saúde Suplementar. Resolução Normativa no 387, de 28 de outubro de 2015. Diário Oficial da União, Brasília, DF, 29 out. 2015. Disponível: http://www.ans.gov.br/component/legislacao/?view=legislacao\& task=TextoLei\&format=raw\&id=MzExMA==. Acesso em: 14 ago. 2017.

BRASIL. Lei no 9.656, de 03 de junho de 1998. Dispõe sobre os planos e seguros privados de assistência à saúde. Diário Oficial da União, Brasília, DF, 04 jun. 1998. Disponível em: http://www.planalto.gov.br/ccivil_03/Leis/L9656.htm. Acesso em: 16 jul. 2017.

CAMPOS, Juliana Cristine Diniz; ALBUQUERQUE, Felipe Braga. Nova hermenêutica constitucional e (in)segurança jurídica: características e críticas da virada linguística no interpretar da situação. Quaestio Iuris, Rio de Janeiro, vol. 08, no 02, p. 774-792, 2015.

CANARIS, Claus-Wilhelm. Pensamento sistemático e conceito de sistema na ciência do direito. Tradução de A. Menezes Cordeiro. 3. ed. Lisboa: Fundação Calouste Gulbenkian, 2002.

COUTINHO, Joana Chagas. Plano de saúde dirigido ao idoso e as consequências da aplicabilidade - §3으, artigo 5으, da Lei oㅜ 10.741/03. In: MARTINS, Guilherme Magalhães (Org.). Temas de Direito do Consumidor. Rio de Janeiro: Lumen Juris, 2010. p. 261-278.

DIAS, Eduardo Rocha. Direito à saúde e informação administrativa: o caso das advertências relativas a produtos perigosos. Belo Horizonte: Fórum, 2008.

DIAS, Eduardo Rocha. Direito à saúde, liberdade de iniciativa e a nova regulamentação do oferecimento de produtos e serviços em farmácias e drogarias. Revista de Direito Público da Economia - RDPE, Belo Horizonte, ano 8, n. 29, p. 73-110, jan./mar. 2010.

DWORKIN, Ronald. Levando os direitos a sério. Tradução de Nelson Boeira. 3. ed. São Paulo: WMF Martins Fontes, 2010. 
GOMES, Josiane Araújo. Contratos de planos de saúde: a busca judicial pelo equilíbrio de interesses entre os usuários e as operadoras de planos de saúde. Leme (SP): JH Mizuno, 2016.

GONÇALVES, Sandra Krieger. Judicialização do direito à saúde e o sistema de saúde suplementar no Brasil: aspectos críticos da fundamentação de decisões judiciais. Rio de Janeiro: Lumen Juris, 2016.

HART, Herbert Lionel Adolphus. 0 conceito de direito. Tradução de Antônio de Oliveira Sette. São Paulo: WMF Martins Fontes, 2009.

KELSEN, Hans. Teoria Pura do Direito. Tradução de João Baptista Machado. 7. ed. São Paulo: Martins Fontes, 2006.

LOPES FILHO, Juraci Mourão. O limite à atuação jurisdicional dos direitos fundamentais com reserva legal. In: ENCONTRO NACIONAL DO CONPEDI, 2010, 19, Fortaleza. Anais do XIX Encontro Nacional do CONPEDI. Florianópolis: Fundação Boiteux, 2010, p. 4476-4487.

MARTINS, Thiago Penido. Contratos de planos de saúde: o direito à saúde nas relações jurídicas entre as operadoras de planos de assistência à saúde e seus beneficiários. Curitiba: Juruá, 2016.

MÜLLER, Friedrich. Teoria estruturante do direito. Tradução de Peter Naumann, Eurides Avance de Souza. 2. ed. São Paulo: Editora Revista dos Tribunais, 2009.

NEVES, Marcelo. Entre Hidra e Hércules: princípios e regras constitucionais. São Paulo: Martins Fontes, 2013.

OLIVEIRA, David Barbosa. A reviravolta linguística na teoria do Direito: a filosofia da linguagem na determinação teórica de Kelsen, Ross e Hart. Revista de Estudos Constitucionais, Hermenêutica e Teoria do Direito (RECHTD), v. 9, n. 2, p. 33-41, jan./abr. 2017.

PÉREZ-LUNO, Antonio Enrique. A desconstrução da lei no constitucionalismo global. Revista de Estudos Constitucionais, Hermenêutica e Teoria do Direito (RECHTD), v. 6, n.2, p.129-141, jul./set. 2014. 
SANTOS, Isabela Soares. O Mix Público-Privado no Sistema de Saúde Brasileiro: elementos para a regulação da cobertura duplicada. 2009. 186 f., Tese (Doutorado em Ciências na área de Saúde Pública). Escola Nacional de Saúde Pública Sergio Arouca, Fundação Oswaldo Cruz, Rio de Janeiro. 2009.

SARLET, Ingo Wolgang; SAAVEDRA, Giovani Agostini. Judicialização, reserva do possível e compliance na área da saúde. Revista de Direitos e Garantias Fundamentais, Vitória, v. 18, n. 1, p. 257-282, jan./abr. 2017.

SARMENTO, Daniel. Direitos fundamentais e relações privadas. 2. ed. Rio de Janeiro: Lumen Juris, 2008.

SHULZE, Clenio Jair. Direito à saúde: novas perspectivas. In: SANTOS, Lanir; TERRAZAS, Fernanda (org). Judicialização da saúde no Brasil. Campinas: Saberes, 2014.

SILVA, Virgílio Afonso da. Regras e princípios: mitos e equívocos acerca de uma distinção. Revista Latino-Americana de Estudos Constitucionais 1 (2003): 607-630.

SUNSTEIN, Cass e VERMEULE, Adrian. Interpretation and institutions. University of Chicago Law School. Coase-Sandor Working Paper Series in Law and Economics, 2002, p. 1-48. Disponível em http://chicagounbound.uchicago. edu/cgi/viewcontent.cgi?article $=1279 \&$ context=law_and_economics. Acesso em 4 de set. de 2017.

STRECK, Lenio Luiz. Verdade e consenso. 5. ed. São Paulo: Saraiva, 2014.

VASCONCELOS, Arnaldo. Teoria da norma jurídica. São Paulo: Malheiros, 2006.

ZAGREBELSKY, Gustavo. El derecho dúctil. 10. ed. Madrid: Editorial Trota, 2011.

Enviado em: 24-10-2017

Recebido em: 26-6-2019 


\section{Eduardo Rocha Dias}

Doutor em Direito pela Universidade de Lisboa; professor do Programa de PósGraduação em Direito Constitucional da Universidade de Fortaleza. Procurador Federal da Advocacia-Geral da União. E-mail: eduardordias@hotmail.com

\section{Mariane Paiva Norões}

Mestranda do Programa de Pós-Graduação em Direito Constitucional da Universidade de Fortaleza - Unifor; pesquisadora-bolsista da Fundação Cearense de Apoio ao Desenvolvimento Científico e Tecnológico (FUNCAP); advogada; e especialista em Direito Civil pela Anhanguera Educação e Participação S.A. E-mail: marianenoroes@hotmail.com Universidade de Fortaleza - UNIFOR Av. Washington Soares, 1321 - Edson Queiroz, Fortaleza - CE, 60811-905 